\title{
SALARIO MÍNIMO REAL Y PIB PER CÁPITA, DETERMINANTES DEL DESEMPLEO EN COLOMBIA 1980 - 2009
}

\author{
EFRAÍN CUADRO GUZMÁN* \\ JORGE LEONARDO CASTILLO LOAIZA** \\ ANDRÉS MAURICIO CASTAÑO ZULUAGA***
}

Recibido 24 de Mayo de 2011/Enviado para Modificación 9 de Noviembre de 2011/Aceptado 30 de Noviembre de 2011

\begin{abstract}
RESUMEN
En el presente estudio, se verifica si las variables Salario Mínimo y PIB Per Cápita, son determinantes de la Tasa de Desempleo en Colombia en el periodo 1980 - 2009, y cuál de las dos variables explica mejor el desempleo que se presenta en este país. En el mismo se encontró que, aumentos en el salario mínimo real, ejercen poca influencia sobre el comportamiento de la tasa de desempleo, caso contrario al impacto que se genera en esta tasa como consecuencia de los aumentos del PIB Per Cápita.
\end{abstract}

Palabras Clave: Salario mínimo real, PIB per cápita en dólares, tasa de desempleo, mercado laboral.

Clasificación JEL: E23, E24, J100, J31, C01, C51.

\begin{abstract}
In the present study is verified if the variables Minimum Wage and GDP Per Capita, are determinants of unemployment rate in Colombia in the period 1980 - 2009, and which of the two variables more acute the unemployment in the country. Also was found that increases in real minimum wage, have little influence on the behavior of the unemployment rate, otherwise the impact that in this rate is generated as a result of increases of GDP per capita.
\end{abstract}

\footnotetext{
* Economista, Docente Investigador del Grupo de Investigación de Mercado Laboral. Correo Electrónico: efracuadro@yahoo.es

${ }^{* *}$ Economista - Universidad de Cartagena. Correo Electrónico: jleonardocasti@hotmail.com

${ }^{* * *}$ Economista - Universidad de Cartagena. Correo Electrónico: landres001@hotmail.com
} 
Keywords: Real minimum wage, GDP per capita in dollars, unemployment rate, labor market.

JEL Classification: E23, E24, J100, J31, C01, C51.

\section{INTRODUCCIÓN}

En Colombia el Salario Mínimo es indiscutiblemente la variable de política laboral que genera la mayor expectativa al final y comienzo de cada año. Anualmente, el gobierno termina decretando el nuevo salario mínimo, después de que la siempre esperada negociación directa entre los trabajadores y los empresarios, fracasa. Dicha modalidad de arreglo institucional, se ha venido aplicando desde 1946 y la expectativa despertada se explica ya que las decisiones que se toman al respecto, se espera impacten a los niveles de empleo, la situación de pobreza y el estado de bienestar de la mayoría de los colombianos.

En la imaginación y en la realidad de los colombianos, está bien claro que el salario mínimo legal vigente, es muy bajo como para cubrir satisfactoriamente las necesidades reflejadas en los bienes y servicios de la canasta familiar. Lo cual induce en parte, a que muchos nacionales se vean obligados entre otras opciones a emigrar hacia otros países en busca de mejores oportunidades de empleo. En contraste con esta realidad, las instancias responsables de las políticas laborales, esgrimen siempre argumentos en contra de ajustes mayores del salario mínimo, considerando que una elevación mayor de éste conlleva a más desempleo, más subempleo y por tanto a más informalidad y pobreza. Paralelamente plantean estas mismas autoridades que el ajuste del salario mínimo siempre tiene en cuenta el ciclo de la economía colombiana, la productividad laboral y el poder adquisitivo de la moneda. Fueron las anteriores inquietudes las que dieron origen a esta investigación, informe final que a continuación se pone a consideración de los amables lectores.

En consecuencia, el contenido de este artículo, se ha estructurado de la siguiente forma: en primera instancia se observará la revisión de la literatura; a continuación se perfilan el marco empírico, el marco teórico aplicado al problema de investigación y un pertinente referente legal; seguidamente se muestran los resultados de la investigación, y al final se presentan las conclusiones y las referencias bibliográficas utilizadas. 


\section{REVISIÓN DE LA LITERATURA}

La revisión del estado del arte, permitió encontrar que existen interesantes trabajos investigativos, en los cuales, el PIB per cápita, el salario mínimo y la legislación laboral, entre otras variables, mantienen una estrecha relación con el desempleo. Entre ellas se presentan aquellas que se estimaron relevantes frente a los objetivos de la investigación.

En el ámbito internacional cabe mencionar el trabajo realizado por Ortega (1), titulado: “CAUSAS DEL DESEMPLEO, SALARIO MÍNIMO Y COSTOS DE LARGO PLAZO". En él, se construye un modelo para Venezuela con un panel de observaciones individuales (Encuesta de Hogares, INE), elaborado desde el primer semestre de 1995 hasta el primer semestre de 1997 y se muestra que el desempleo afecta en mayor cuantía a las personas de niveles más bajos, además, se determina que entre menor es el nivel educativo de los trabajadores, mayor es la probabilidad de caer en desempleo y que las personas con menor experiencia laboral son más vulnerables. Por otra parte, se encontró que el efecto del salario mínimo sobre la probabilidad de quedar desempleado es positivo, pero en muchos casos no es estadísticamente significativo y que el efecto es mayor en el sector formal que en el informal.

A nivel nacional, se registra a Núñez y Bonilla (2), quienes teniendo en cuenta las etapas rotativas de la encuesta de hogares del DANE de 1997 y 1998, realizan su investigación titulada ¿QUIÉNES SE PERJUDICAN CON EL SALARIO MÍNIMO EN COLOMBIA?; en ésta estimaron la elasticidad del empleo al salario mínimo en -0.23 y la probabilidad que los colombianos tienen de estar empleados. Con ello lograron encontrar, que el salario mínimo tenía un efecto negativo sobre el empleo y que quienes resultan más afectados son los trabajadores cuyo salario es inferior al mínimo. A su vez, establecen que la probabilidad de perder el empleo es aún mayor, cuando los individuos devengan un salario cercano al mínimo.

Así mismo, en su trabajo investigativo "EMPLEO Y DESEMPLEO EN COLOMBIA: EL IMPACTO DE LA LEGISLACIÓN LABORAL Y DE LAS POLÍTICAS SALARIALES (1976-1999)", Robbins (3) establece que los cambios en la legislación laboral y en el salario mínimo y la supuesta rigidez en la fijación de salarios no fueron los causantes del aumento del desempleo presentado a partir de 1994. Así mismo, encontró que no existía un excesivo crecimiento en los costos laborales totales, como para haber disminuido la creación de empleo o aumentar la tasa de desempleo. Por 
consiguiente, Robbins (3) concluye que con modificar las reformas laborales o el salario mínimo, no es posible solucionar el problema del desempleo en Colombia en el corto o en el mediano plazo. Así mismo, considera que para resolver los problemas de baja productividad, estancamiento y desempleo, es importante la implementación de una reforma al sector financiero, la regulación anti-monopolio, las políticas keynesianas para reactivar la economía y la mayor eficiencia en la provisión de servicios financiados vía costos laborales no salariales.

Por otra parte, se puede también citar el trabajo de Ruiz (4) denominado "SALARIO MÍNIMO: CONSIDERACIONES ECONÓMICAS Y SOCIALES PARA SU DETERMINACIÓN", en el que se pretendió sistematizar los distintos argumentos que normalmente se utilizan durante la discusión sobre el monto del salario mínimo en Chile e identificar los posibles impactos que resultan de su determinación. De esta manera, se pudo identificar varios tipos de argumentos que se utilizan en el debate para establecer el salario mínimo, entre los cuales se encuentran: el efecto que puede tener en mejorar el nivel de ingreso de los hogares más pobres, los efectos sobre el empleo de los trabajadores no calificados, particularmente sobre las posibilidades de inserción laboral de los jóvenes y el impacto sobre el nivel general de salarios, y consecuentemente sobre la relación entre salario y productividad laboral. Por otra parte, dicho trabajo investigativo logró identificar que durante los años noventa, en que el PIB chileno crecía a una tasa promedio de $6,7 \%$, se presentaba un sostenido incremento de los salarios mínimos reales urbanos, los cuales crecían $4,5 \%$ como promedio anual, mientras que el desempleo abierto urbano lo hacía al 6,8\%. A fines de 1999, el desempleo abierto llegaba al 9,8\%; por lo tanto, el PIB tendió a crecer al tiempo que aumentaba el desempleo abierto y que se incrementaban los salarios mínimos urbanos reales. De igual manera, nota que uno de los factores que explican la evolución del mercado laboral tiene que ver con el comportamiento del sector empresarial que, en vez de contratar nuevos trabajadores, buscó mejorar la productividad de sus empleados mediante inversiones en tecnología, capacitación de la fuerza de trabajo, entre otras; así mismo, se establece que la tendencia alcista del salario mínimo real no es explicada por la capacidad del sindicalismo para obtener dicha mejoría, sino que es atribuible a las decisiones que la autoridad económica tomó para aprobar en el parlamento durante el primer sexenio de los años noventa, importantes incrementos del salario mínimo.

Otra investigación de importancia se atribuye a Hernández y Pinzón (5), quienes realizan su estudio: “EL EFECTO DELSALARIOMÍNIMOSOBRE 
EL EMPLEO Y LOS SALARIOS" y utilizando en ella la metodología "pooled panel" con la Encuesta Continua de Hogares (DANE) entre 2000 y 2004, en el cual estiman la probabilidad que tienen los colombianos de estar empleados. Contrario a lo que establecieron Núñez y Bonilla (2), Hernández y Pinzón (5) encontraron que el salario mínimo si tiene un efecto positivo sobre el empleo, específicamente en las personas entre los 18 y 25 años de edad, dado que un incremento del 10\% en el salario mínimo incrementa el empleo de dicha población en un 15.9\%. Según los autores, lo anterior puede atribuirse a la sustitución de la demanda laboral de adultos por jóvenes, debido a que los costos de contratación de estos últimos, son menores a la de los de adultos; además, cabe aclarar que existe la posibilidad de que los resultados obtenidos pueden estar siendo afectados, dado que en el estudio se analizan solamente los ingresos y no los salarios de las personas, así como tampoco se tienen en cuenta el número de horas trabajadas.

Por su parte, en el trabajo de Steiner y Gracia (6) titulado ¿POR QUÉ SE REQUIEREN REFORMAS AL MERCADO LABORAL Y AL SISTEMA PENSIONAL?, se discuten las causas de la segmentación del mercado laboral y de los elevados niveles de desempleo, se analiza la estructura del sistema pensional y se estudia la relación entre las restricciones del mercado laboral y los problemas que lo aquejan. En él se establece que Colombia es un país de ingreso medio - bajo; el ingreso per cápita es apenas de un $10 \%$ del de los Estados Unidos y menos de la mitad del observado en Venezuela, México y Chile. Como reflejo de ello, no es de sorprender que todos los salarios del país, incluido por supuesto el salario mínimo, sean más bajos en términos absolutos. A través de este trabajo se mostró que el nivel y la forma como se incrementa el salario mínimo en Colombia tienen efectos negativos sobre el empleo, la informalidad, la distribución del ingreso y, en general, sobre el bienestar de la población, especialmente la de menores ingresos.

Finalmente, resaltando que el propósito de las políticas salariales a nivel nacional e internacional deben enfocarse en la mejora de la situación laboral de los trabajadores y en la creación de empleo, cabe mencionar los esfuerzos que realiza la política salarial del gobierno de Ecuador con el proyecto del Código de la Producción que se encuentra en proceso de aprobación por parte de la Asamblea Nacional, y en el que se pretende establecer el Salario Digno para los trabajadores, el cual se estima alcance los USD 320, y dado que el salario básico se encuentra en los USD 240 mensuales, la diferencia entre el salario digno y el básico deberá ser cubierta por las utilidades de las propias empresas a través de un bono. 
Lo anterior ha causado temores por parte del sector trabajador, ya que se especula que en vez de mejorar la situación laboral esto conlleve a despidos posteriores, ahondando así el desempleo que a diciembre de 2009 se ubicó en $7,90 \%$ (1).

\section{MARCO EMPÍRICO}

En el escenario laboral colombiano se presentan situaciones de carácter friccional, estructural y cíclico que impiden la articulación de la oferta y demanda de trabajo, razones determinantes que permiten encontrar para Colombia, una tasa de desempleo de más de once puntos porcentuales para diciembre de 2009, a lo que se le suma un alto grado de informalidad, precariedad, y pésimas condiciones en los lugares donde a las personas les toca desarrollar sus respectivas actividades labores. En este marco desfavorable en términos generales, se puede afirmar que la retribución que obtienen a cambio de su mano de obra, es muy baja en comparación con el costo de vida del país y con las condiciones del entorno.

Lo anterior, contrasta con la teoría económica en el sentido que, si se aumentan los salarios -entre ellos el salario mínimo real-, se generaría un encarecimiento de la mano de obra y por lo tanto, una agudización del desempleo. O lo mismo pero desde otra óptica: "si disminuyen los salarios, se abaratarán los costos laborales y por ende aumentaría la contratación de trabajadores, bajando el desempleo". En cualquier escenario, el componente más importante de los costos laborales son los salarios, como unidad de precio de la oferta laboral.

La presente investigación busca verificar en qué medida el salario mínimo real y el PIB per cápita en pesos, determinan la tasa de desempleo de Colombia durante el periodo 1980 - 2009. Tal problema investigativo se aborda inicialmente, mediante un análisis descriptivo de las variables Salario Mínimo Real, PIB Per Cápita en dólares y Tasa de Desempleo de Colombia en el periodo de estudio. Y como segundo paso, se demuestra mediante la formalización de un modelo econométrico correlacional, la influencia que podrían tener las variables Salario Mínimo Real y PIB Per Cápita en dólares sobre la Tasa de Desempleo en Colombia en el periodo 1980 - 2009.

Se parte de la hipótesis que, "la tasa de desempleo de Colombia en el periodo 1980 - 2009, es determinada por los aumentos en el salario mínimo, y por las variaciones del PIB per cápita", lo cual puede observarse en las elasticidades que tienen cada una de estas dos variables respecto a la variable Tasa de Desempleo en Colombia. 
TABLA 1. OPERACIONALIZACIÓN DE LAS VARIABLES

\begin{tabular}{|l|l||l||}
\hline \multicolumn{1}{|c|}{ Variable } & \multicolumn{1}{|c||}{ Indicador } & \multicolumn{1}{c||}{ Fuente } \\
\hline Salario mínimo real & (salario mínimo nominal año n/ IPC año n)*100 & DANE, CEPAL \\
\hline $\begin{array}{l}\text { PIB per cápita en } \\
\text { dólares }\end{array}$ & $\begin{array}{l}\text { PIB total en pesos / cantidad de habitantes de la } \\
\text { economía/ tasa de cambio al periodo } \mathrm{n}\end{array}$ & DANE, Banco mundial \\
\hline Tasa de desempleo & $\mathrm{Td}=\left(\mathrm{N}^{\circ} \mathrm{D} / \mathrm{PEA}\right)^{*} 100$ & DANE, Banco mundial \\
\hline
\end{tabular}

Fuente: Diseño de los Autores.

La investigación fue de carácter descriptiva y correlativa, porque estuvo dirigida a responder si el PIB Per Cápita en dólares y el Salario Mínimo en términos reales, determinan el comportamiento de la tasa de desempleo en Colombia en el periodo 1980 - 2009.

El diseño de esta investigación fue de carácter no experimental, pues no se construyó una situación, sino que se estudiaron situaciones ya existentes (3). Además fue de tipo longitudinal de tendencia, porque se analizaron cambios a través del tiempo de las variables, en este caso de agregados económicos estipulados por el grupo investigador (8).

Se utilizó el método descriptivo para especificar las propiedades y características de las variables a estudiar, posteriormente se utilizó el método correlativo para relacionar las variables entre sí, todo lo anterior sobre la base de un análisis histórico, estudiando las estadísticas del comportamiento de las variables empleadas en el tiempo (1980 - 2009) (8). Y en última instancia, se realizó un análisis ex post facto, para examinar la forma cómo las variables que explican la tasa de desempleo, efectivamente la determinan.

Las tablas, las figuras de tendencias y los promedios, se efectuaron con el programa Microsoft Office Excel 2010.lnk, mientras que los análisis de regresión y las pruebas de normalidad, multicolinealidad, heteroscedasticidad, autocorrelacion y especificación del modelo, se realizaron utilizando el software Econometric View versión 5.1. Todas las pruebas se efectuaron con un nivel de significancia del $5 \%$, es decir con un coeficiente de confianza del $95 \%$. Además, se aplicó como método para las estimaciones del modelo, el de los mínimos cuadrados ordinarios (L.S - Least Squares), empleando para esto el software Econometric View versión 5.1 .

La primera fase se análisis investigativo, consistió en construir gráficos de tendencias de las variables del modelo en estudio (salario mínimo real, tasa de desempleo y PIB per cápita en dólares). En segunda instancia, utilizando el software Econometric View versión 5.1, se realizaron figuras 
individuales de dispersión con regresión (scatter with regression) entre la variable explicada (tasa de desempleo), y cada una de las variables explicativas (salario mínimo real y PIB per cápita en dólares), con el propósito de dar un bosquejo inicial acerca de las relaciones entre las variables y poder ver si éstas se validan a través del soporte teórico.

Posteriormente, se ejecutaron todas las pruebas pertinentes que permitieron detectar problemas de normalidad, multicolinealidad, heteroscedasticidad, autocorrelacion y especificación del modelo, efectuándose las siguientes pruebas:

- prueba Normalidad a través del Estadístico Jarquer-Bera.

- prueba de Multicolinealidad por medio de la matriz de correlaciones.

- prueba de Heteroscedasticidad, en primera instancia por medio del método gráfico, y luego se realizó una prueba más formal como la de White.

- prueba de Autocorrelacion, a través del estadístico Durbin y Watson,

- prueba de Especificación del modelo a través de la prueba RESET de Ramsey.

El modelo planteado fue de la forma:

$$
\mathrm{TD}=\beta_{1}+\beta_{2} \mathrm{SMR}+\beta 3 \mathrm{PPC} \text { Donde: }
$$

$\mathrm{TD}=$ Tasa de desempleo $(\%)$.

$\mathrm{SMR}=$ salario mínimo real (en pesos). Se espera una relación positiva.

PPC= PIB per cápita (en dólares), se espera una relación negativa.

\section{MARCO TEÓRICO}

En la teoría económica se resaltan regularmente, cuatro puntos de vista para mirar el efecto que tiene el salario mínimo sobre el empleo: el modelo competitivo de oferta y demanda, el modelo de monopsonio [Stigler, (1946) realiza una primera referencia a estos modelos en el contexto del salario mínimo], el de salarios de eficiencia y el de búsqueda. A continuación se muestra de manera sintetizada los fundamentos que se derivan de cada uno de estos modelos. 


\section{EL MODELO COMPETITIVO}

En el mercado laboral competitivo, el salario se determina a través de la interacción de la demanda y la oferta como se muestra en la Figura 1. El resultado que se obtiene es un salario uniforme ( $W o$ o el cual se paga por todas las empresas y se recibe por todos los trabajadores (se supone que estos tienen la misma dotación de capacidades y/o habilidades). A este nivel salarial, el número de personas que desean trabajar es exactamente igual al número de trabajadores que los empleadores quieren contratar (Lo).

$\mathrm{Al}$ introducir un nivel de salario mínimo $(\mathrm{Wm})$ que se encuentra por encima del salario que equilibra al mercado, la cantidad ofrecida aumenta (a L1) mientras que la demandada disminuye (a L2), por tanto se genera un exceso de oferta (representado por L1 - L2). El salario mínimo establecido impide que exista un nivel de equilibrio ya que no se puede eliminar el exceso de oferta a dicho salario $(\mathrm{Wm})$. Finalmente lo que sucede es que con esta rigidez se genera el desempleo involuntario (1).

\section{FIGURA 1. DETERMINACIÓN DEL SALARIO EN UN MERCADO} COMPETITIVO Y SALARIO MÍNIMO

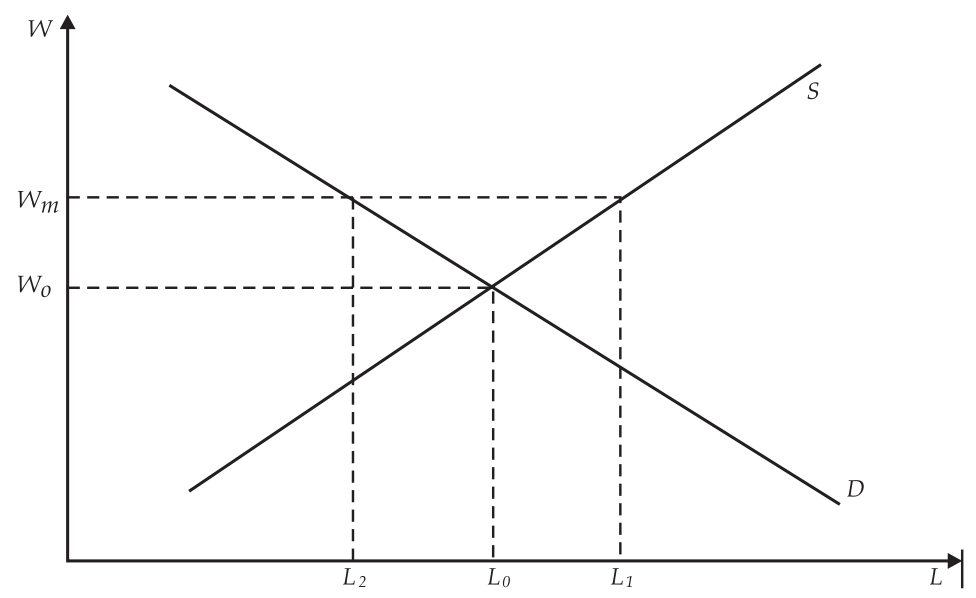

Fuente: ensayos sobre política económica. Banco de la República 2008; 23 (56)

\section{El salario mínimo en una economía con dos sectores bajo el modelo competitivo}

El análisis de los efectos del salario mínimo se puede ampliar a una economía con dos sectores productivos: uno que se ajusta a toda la normatividad, denominado "sector cubierto" (que puede asimilarse al "formal"), y otro que no cumple con las disposiciones (o en el cual estas no rigen, como fue usual en varias actividades en Estados Unidos) y que denominamos "sector 
no cubierto". Por ejemplo, si una de las normas es el pago de un salario mínimo por período de tiempo $(\mathrm{Wm})$, habrá unas empresas que lo hagan y otras que no. Estas últimas son las que, en este esquema simple, identifican el sector no cubierto (Welch, 1974; Mincer, 1976). De acuerdo con lo anterior, es de esperarse que algunos trabajadores que pierden su trabajo en el sector cubierto, como consecuencia de la introducción del salario mínimo, sean absorbidos por el sector no cubierto, reduciendo así el salario en éste último.

FIGURA 2. EFECTO DEL SALARIO MÍNIMO EN UNA ECONOMÍA DE DOS SECTORES

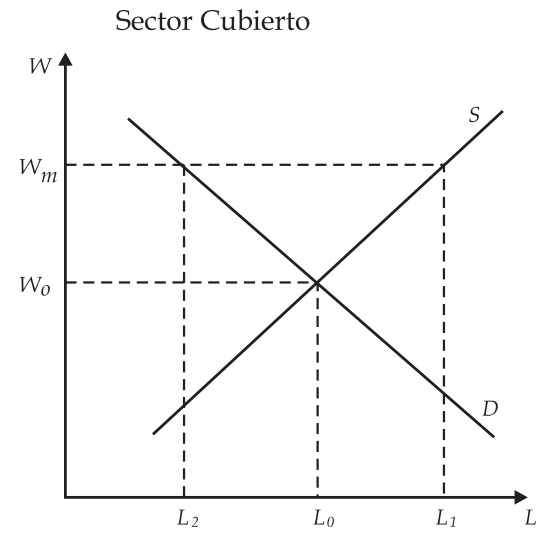

Sector Cubierto
Sector No Cubierto

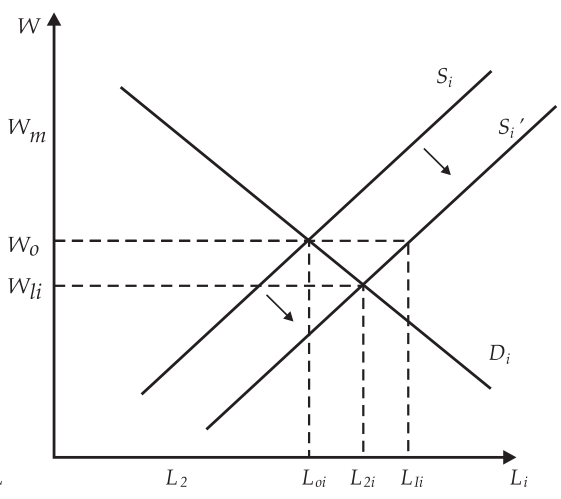

Sector No Cubierto

Fuente: ensayos sobre política económica. Banco de la República 2008; 23 (56)

Esta situación se representa en la Figura 2, por medio de un desplazamiento de la curva de oferta de trabajo en el sector no cubierto lo cual causa una caída en el salario que se paga en dicho sector y un aumento en el empleo. Sin embargo, estos pueden no ser los efectos: la dirección en la cual se mueve el trabajo entre los sectores, el nivel de desempleo y el diferencial de salarios dependen de la elasticidad de la demanda de trabajo de los dos sectores, de la elasticidad de la oferta de trabajo total, de la cobertura del salario mínimo y de la tasa de vacantes en el sector formal (Mincer, 1976).

\section{El salario mínimo en un modelo de monopsonio}

Un caso diferente al modelo competitivo es el de monopsonio (un solo demandante de mano de obra; Stigler, 1946). Un monopsonio ejerce su poder de mercado pagando un salario menor al que se pagaría en un mercado competitivo. Un monopsonista no puede adquirir una cantidad ilimitada de un insumo a un precio uniforme; el precio que debe pagar por cada unidad adquirida viene dado por una curva de oferta del mercado del insumo; es decir, el precio que tiene que pagar el monopsonista es función creciente de la 
cantidad que adquiera [ $\left.w=w(L) ; w^{\prime}>0\right]$. A diferencia del caso competitivo, en el cual la firma se enfrenta a una curva de oferta horizontal, la curva de oferta que enfrenta un monopsonio tiene pendiente positiva. Es decir, mientras que una empresa en competencia perfecta puede contratar todos los trabajadores que quiera a un salario de mercado, que es dado para ella, el monopsonio no puede hacerlo; si desea contratar un trabajador adicional debe pagar un salario mayor para atraerlo. Debido a que el monopsonio debe pagar el mismo salario a todos los trabajadores-incluyendo los que ya tenía contratados- el costo marginal del último trabajador contratado ( $C M$ ) es mayor que el salario que recibe este trabajador, tal como se observa en la Figura 3.

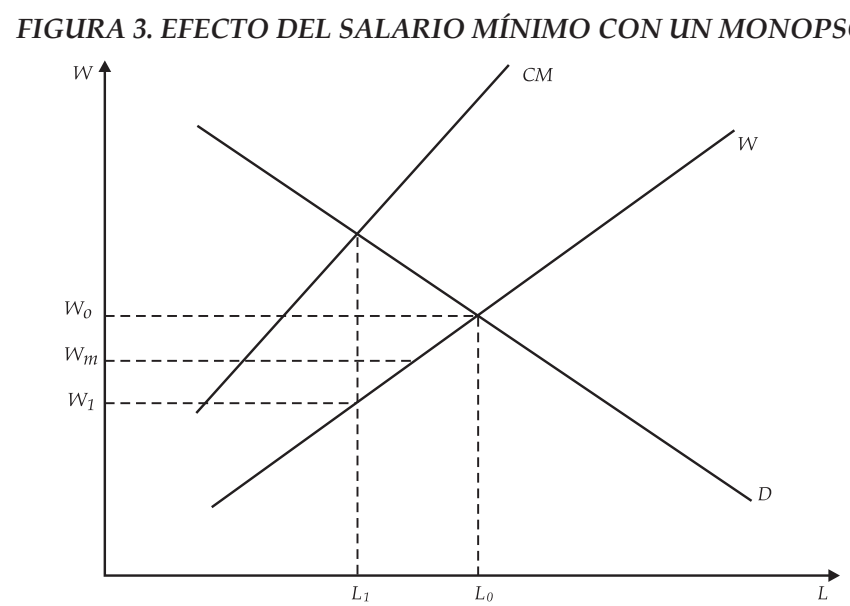

Fuente: ensayos sobre política económica. Banco de la República 2008; 23 (56)

El monopsonio maximizador de beneficios contrata trabajo hasta el nivel en el cual la curva de $C M$ corta la curva de demanda por trabajo $(D)$; dado esto, el salario es determinado por la curva de oferta $(W)$. Si se compara este resultado con el de un equilibrio competitivo, se encuentra que la cantidad de trabajo contratado y (probablemente) los salarios, son menores en un mercado monopsónico. Al introducir un salario mínimo $(\mathrm{Wm})$ en un mercado monopsónico, el empleador se convierte en un tomador de precios y cualquier trabajador que contrate gana un salario igual al mínimo. Es decir, el costo marginal de contratar un trabajador se vuelve constante. $\mathrm{Si}$ el salario mínimo es fijado por encima del salario de monopsonio, pero por debajo del de competencia perfecta, el nivel de empleo aumenta y el salario también. Sin embargo, si el salario mínimo es fijado por encima del salario de competencia perfecta el empleo se puede reducir a un nivel inferior al del caso competitivo. Brown, Gilroy y Kohen (1982) señalaron que el modelo de monopsonio no había dado lugar a muchas investigaciones. Sin embargo, al analizar los efectos del aumento del salario mínimo federal en 1991 sobre 
el empleo de la industria de comidas rápidas en Texas, y del aumento del salario mínimo en julio de 1988 sobre el empleo de baja calificación en California, respectivamente, Katz y Krueger (1992) y Card (1992) acudieron a la posibilidad de que sus resultados estuvieran indicando la existencia de poder de monopsonio en el mercado de trabajo de baja calificación.

\section{El salario mínimo y la teoría de salarios de eficiencia}

La teoría de salarios de eficiencia afirma que, dados unos altos costos de monitoreo del esfuerzo de los trabajadores, una manera de incrementar la productividad y combatir la actitud elusiva de estos en materia de esfuerzo laboral consiste en establecer un salario superior al de equilibrio. Bajo esa perspectiva, mayores salarios traerán como resultado mayor empleo. Un salario más alto mejora el esfuerzo de los trabajadores y reduce el riesgo moral; por tanto, cuanto más alto sea el salario, mayor será el costo para un trabajador de ser despedido (Rebitzer y Taylor, 1995). El empleador encuentra que la fuerza laboral existente ya no requiere una supervisión tan intensa para asegurar un comportamiento no evasivo. Esto libera recursos de las actividades de supervisión y permite a la firma contratar un mayor número de trabajadores sin incrementar los salarios para los trabajadores intra-marginales. Como resultado, un salario mínimo escogido adecuadamente podría introducir una mejora paretiana. La Figura 4 ilustra el efecto en el modelo y hace evidente el supuesto de que la firma enfrentaría una curva de oferta laboral de pendiente positiva respecto al salario excepto si rige por ley un salario mínimo (un caso similar al del monopsonista).

\section{FIGURA 4. EFECTO DEL SALARIO MÍNIMO BAJO SALARIOS DE EFICIENCIA}

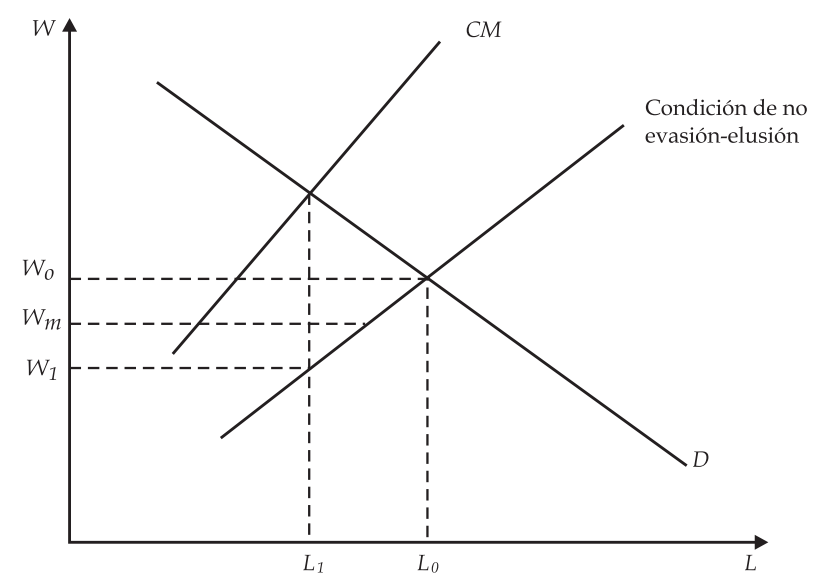

Fuente: ensayos sobre política económica. Banco de la República 2008; 23 (56) 


\section{Justificaciones para los salarios de eficiencia}

- Teoría de "Shirking": si el empleador no observa el esfuerzo de los trabajadores, pagar salarios de eficiencia puede incentivar a los trabajadores a esforzarse. En el modelo de Shapiro y Stiglitz (1984), los trabajadores pueden escoger entre esforzarse o no. Si no se esfuerzan, hay una probabilidad de ser sorprendidos y la sanción es el despido. Así, con el fin de asegurar un nivel mínimo de productividad, el empresario fijará un salario que incentive a los trabajadores a desempeñar sus tareas con la intensidad requerida por la empresa (3).

- Modelos de rotación laboral: para las empresas, la rotación es costosa. Dado esto, las empresas pueden ofrecer salarios en exceso al salario de equilibrio para reducir los costos de la rotación. A mayor salario, menor será la probabilidad de rotación en la empresa. Campbell (1993) realiza un modelo teórico en el que los salarios están afectados únicamente por los costos de rotación. Concluye que las firmas sí pagan salarios de eficiencia, es decir, que las firmas en las que los costos de rotación son más altos, los salarios también son más altos.

- Modelos de selección adversa: en estos modelos, un mayor salario atrae a postular por un empleo de la empresa a los trabajadores más hábiles. Caraballo (1996) plantea que el desempleo se genera cuando el salario que iguala la oferta de trabajo con la demanda es inferior al salario de eficiencia porque no constituye una situación de equilibrio. Esto se da ya que si todas las empresas ofrecen el salario competitivo, una empresa cualquiera que decida pagar el salario de eficiencia atraerá a los mejores trabajadores, por lo que los costos descenderán y los beneficios aumentarán con relación a las demás empresas. Si el salario competitivo es superior al salario de eficiencia, el equilibrio viene determinado por el salario competitivo porque una empresa que ofrezca el salario de eficiencia no atraerá a los trabajadores. En definitiva, este modelo ayuda a comprender la dificultad de los desempleados de larga duración para reincorporarse al mercado laboral.

- Modelos sociológicos: el esfuerzo de un trabajador depende de las normas laborales de su grupo. Una empresa, en este contexto, puede pagar un salario mayor que el equilibrio con el objeto de elevar los estándares laborales del grupo, de sus normas y el esfuerzo promedio. Como modelo sociológico, destaca lo que es el salario justo. Akerlof y Yellen $(1988,1990)$ plantean la hipótesis de que el salario justo se refiere a la concepción del trabajador sobre el salario justo que debería percibir 
un salario wj. Si es superior al salario que actualmente está recibiendo, w, ejercerá un esfuerzo proporcionalmente menor, de forma que el nivel de esfuerzo será e $=\min \{w / w j, 1\}$, si el salario justo está por encima del salario que vacía el mercado, habrá desempleo.

\section{El salario mínimo y el modelo de búsqueda}

El efecto del salario mínimo sobre el empleo depende, en este contexto, de manera crucial del salario de reserva, del esfuerzo de búsqueda y de las propiedades de la función de distribución de los salarios ofrecidos. Van den Berg y Ridder (1998), apoyados en Burdett y Mortensen (1998), presentan un modelo de búsqueda de equilibrio en el cual la distribución de ofertas salariales es endógena. Ello resulta de una determinación de salarios por parte de las firmas que toma en cuenta las respuestas de los buscadores de trabajo y de las otras firmas. Los hallazgos de Van den Berg y Ridder (1998) sugieren que en un mercado de trabajo segmentado, con suficiente heterogeneidad en el flujo de ingresos de un trabajador empleado, un salario mínimo uniforme que exceda el nivel de productividad de algún segmento puede fácilmente causar desempleo ya que las firmas, en ese segmento, dejarían de ser rentables (9).

Por otro lado, Cahuc y Zylberberg (2004) sugieren que ante un aumento del salario mínimo, la diferencia entre las ganancias esperadas de un empleado y un desempleado aumenta. Esto genera un incentivo para que estos últimos hagan una búsqueda más intensa de trabajo y se incremente la tasa de salida de desempleo; esto reduce la tasa de desempleo. Sin embargo, el salario mínimo también ejerce una influencia adversa sobre el empleo ya que los costos laborales se incrementan. El efecto final sobre el empleo es ambiguo (9).

\section{MARCO LEGAL DEL SALARIO MÍNIMO COLOMBIANO}

El salario mínimo en Colombia, fue legalmente constituido mediante la Ley $6^{\mathrm{a}}$ de 1945, cuyo artículo $4^{\circ}$ dispone que "el gobierno podrá señalar, por medio de decretos que regirán por el término que en ellos se indique, los salarios mínimos para cualquier región económica o cualquier actividad profesional, industrial, comercial, ganadera o agrícola de una región determinada, de conformidad con el costo de la vida, las modalidades del trabajo, la aptitud relativa de los trabajadores, los sistemas de remuneración o la capacidad económica de las empresas, previo concepto de comisiones paritarias de patronos y trabajadores" (6). Sin embargo, la ley no se hizo efectiva sino en 1949; en ese año, por medio del Decreto 3871, se fijó por primera vez en Colombia el salario mínimo: su valor fue de dos pesos diarios. 
Anteriormente y hasta mediados de la década de los 80 existía una amplia gama de salarios mínimos. Por ejemplo, el decreto 236 de 1963 (que reglamentaba la Ley $1^{\text {a }}$ de 1963) estableció salarios por departamentos y tamaños de empresa; el decreto 240 de ese mismo año reajustó el salario mínimo en el sector agrícola y de los trabajadores menores de dieciséis años. El decreto 577 de 1972 fijó salarios por sector, por zona del país y por tamaño de empresa, etc. La unificación del salario mínimo se produjo en 1983 (decreto 3506). El proceso de ajuste culminó el $1^{\circ}$ de julio, fecha a partir de la cual hubo un salario mínimo para la totalidad de los trabajadores colombianos (9).

Por otro lado, el artículo 53 de la Constitución Política de 1991, correspondiente al capítulo 2 sobre los derechos sociales, económicos y culturales, señala que la ley laboral deberá tomar en cuenta la "remuneración mínima vital y móvil, proporcional a la cantidad y calidad de trabajo como uno de sus elementos básicos" (3). En la actualidad, la Comisión Permanente de Concertación de Políticas Laborales y Salariales es la encargada de proponer el salario mínimo a finales de cada año. Dicha comisión está conformada por igual número de representantes del gobierno, los empleadores y los trabajadores. De ella forman parte: a) en representación del Gobierno: el Ministro de Protección Social o su delegado, quien la presidirá, el Ministro de Hacienda y Crédito Público o su delegado, el Ministro de Comercio Exterior o su delegado, el Ministro de Agricultura o su delegado, el Director del Departamento Nacional de Planeación o su delegado; b) por los empleadores: cinco representantes con sus respectivos suplentes personales, designados por las asociaciones nacionales gremiales más representativas de empleadores de los distintos sectores económicos del país, en forma ponderada y de conformidad con la participación de cada sector en el producto interno bruto y en la generación de empleo. Para ello, el Gobierno se basará en los datos y cifras elaboradas por el Departamento Administrativo Nacional de Estadística; c) por los trabajadores: cinco representantes con sus suplentes personales, designados o removidos por las confederaciones sindicales más representativas del país, determinadas con base en el número de afiliados que cada una de éstas posea al momento de la elección, según censo que en tal sentido elabore el Ministerio de la Protección Social, y dentro de los cuales habrá por lo menos un representante con su respectivo suplente, de los pensionados, que se rotará cada cuatro años entre las dos Confederaciones de Pensionados más representativas (9).

De acuerdo con la Ley 278 de 1996, “...la comisión debe fijar de manera concertada el salario mínimo teniendo en cuenta la meta de inflación del siguiente 
año fijada por la Junta del Banco de la República, la productividad acordada por el comité tripartito de productividad que coordina el Ministerio de Protección Social, la contribución de los salarios al ingreso nacional, el incremento del producto interno bruto y el indice de precios al consumidor (IPC)" (8). La norma establece que las decisiones de la Comisión serán adoptadas por consenso. El voto de cada sector representativo es el de la mayoría de sus miembros. Para la fijación del salario mínimo, la Comisión debe decidir a más tardar el quince de diciembre. Si no es posible concertar, la parte o partes que no estén de acuerdo deben explicar las razones de la salvedad dentro de las cuarenta y ocho horas siguientes. Las partes tienen la obligación de estudiar esas salvedades y fijar su posición frente a ellas en el término de las siguientes cuarenta y ocho horas. De nuevo, la Comisión debe reunirse para buscar el consenso según los elementos de juicio que se hubieren allegado antes del treinta de diciembre. Cuando no se logre el consenso en la fijación del salario mínimo, para el año inmediatamente siguiente, a más tardar el treinta de diciembre de cada año, el gobierno lo determinará teniendo en cuenta como parámetros la meta de inflación del siguiente año fijada por la Junta del Banco de la República y la productividad acordada por el comité tripartito de productividad que coordina el Ministerio de Protección Social; además, la contribución de los salarios al ingreso nacional, el incremento del producto interno bruto, la meta de inflación y la inflación observada (9).

\section{RESULTADOS DE LA INVESTIGACIÓN}

Las variables anteriormente expuestas para el desarrollo del modelo econométrico, presentan ciertas tendencias y ciertos comportamientos que se explican principalmente por acontecimientos de carácter político, social y económico que se fueron manifestando de manera secuencial de acuerdo al periodo de estudio de esta investigación. En este orden de ideas, en primer lugar se procederá a describir la Tasa de desempleo (TD), su evolución y algunas de las causas por las cuales presentó la tendencia que se explica a continuación.

\section{Tasa de desempleo en Colombia:}

Como se puede observar en la Figura 5, la tasa de desempleo en Colombia presenta un mínimo de $8,1 \%$ en el año de 1981, y un valor máximo de $20,5 \%$ en el año 2000 seguido por 20,1\% en 1999, por lo cual presenta un rango total de 12,4\% en el período 1980 - 2009. Este valor de 20,5\%, que fue de gran alarma para el Gobierno y todos los estamentos sociales en ese año, se debió principalmente a la fuerte crisis económica que presentaba Colombia desde el año 1999, la cual se caracterizó por un deterioro del 
Crecimiento del PIB que fue atribuido a varias razones entre las que se resaltan; una masiva entrada de capitales que revaluaban la tasa de cambio, acompañada esta situación por un gasto publico desbordado. Estos tres aspectos entre los más relevantes, terminaron por crear una serie de desequilibrios macroeconómicos que se manifestaron al comienzo como burbujas especulativas en los mercados de finca raíz y accionarios.

Además, "La crisis internacional desatada por la moratoria rusa de agosto de 1998, encontró al país muy vulnerable en sus cuentas fiscales y con un sector privado endeudado externa e internamente en grandes magnitudes, por lo cual la suspensión súbita del financiamiento externo indujo a una contracción del PIB del 4,3\% en 1999" (7). A todo lo anterior, le agregamos la incertidumbre política del gobierno del presidente Ernesto Samper cuando fue acusado de recibir \$6 millones de dólares de parte del Cartel de Cali, las altas tasas de interés, y el remezón en el sistema financiero. Los puntos anteriores fueron los detonantes de una de las más grandes crisis que ha padecido la economía colombiana en toda su historia.

FIGURA 5. TASA DE DESEMPLEO DE COLOMBIA 1980 - 2009

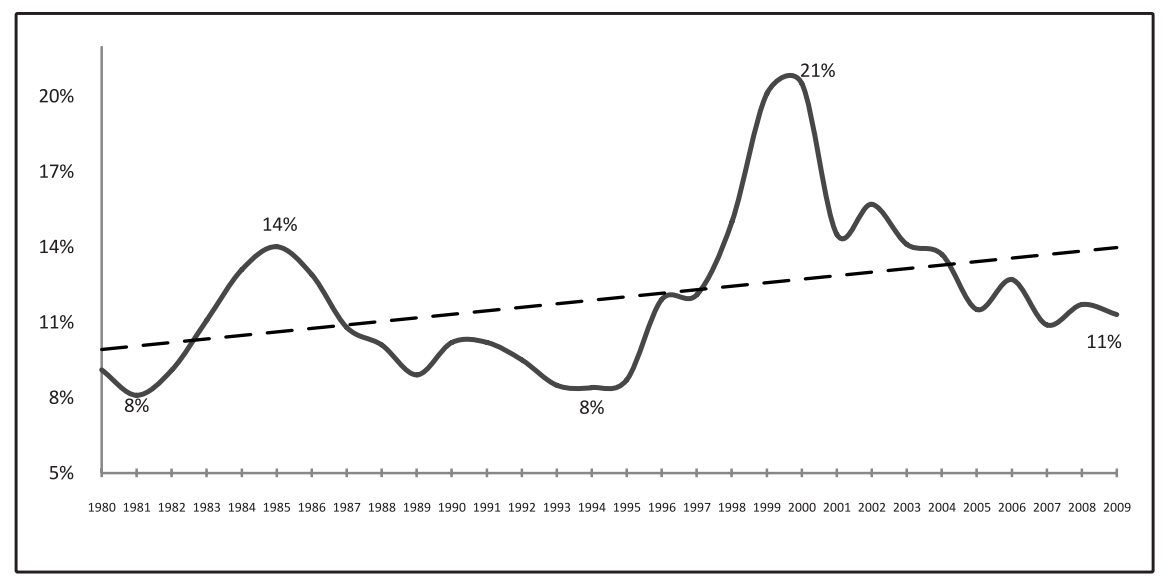

Fuente: diseño de los autores con base en estadísticas del Banco Mundial (5)

A raíz de esta serie de acontecimientos, en 1999 las 300 empresas más grandes de Colombia redujeron en un 3,8\% el total de los puestos generados. En otras palabras, suprimieron 18.300 empleos, situación que contribuyó a elevar los índices de desocupación, tal como lo muestra la Figura 5, de un $15 \%$ en 1998 hasta un 20,5\% en el 2000. El período de crecimiento de la Tasa de Desempleo desde un 9,1\% en 1980 hasta antes del año de 1998, presenta una media de 10,6\%, es decir la tasa de desempleo fluctuó muy poco en esos años, sin embargo, se dispara gracias a la crisis general de Colombia en los 
años 1999 y 2000. Sin embargo, el período siguiente 2001- 2009, comienza con una disminución de seis puntos porcentuales en la Tasa de Desempleo, es decir, de un $20,5 \%$ a un $14,5 \%$, y sigue un comportamiento tendiente a disminuir. Lo curioso a analizar es esa disminución tan repentina de la tasa de desempleo después de una crisis como la que sufrió Colombia. Muchos analistas sugieren que entre otras determinantes, la razón de ser de esta disminución, obedeció en gran medida, al cambio de la metodología para medir el desempleo utilizado por el DANE, que además de reemplazar la Encuesta Nacional de Hogares (ENH) por la Encuesta Continua de Hogares $(\mathrm{ECH})$, consideró que una persona que no está interesada en buscar trabajo, entra a formar parte de la Población Económicamente Inactiva (PEI), por ende, todas las personas que no están interesadas en trabajar disminuyen la Población Económicamente Activa (PEA), pero también disminuye la población desocupada (desempleada) en la misma proporción, lo que disminuye la tasa de desempleo que se calcula con base en el total de la PEA.

Durante el resto del período 2002 hasta el 2009, la tasa de desempleo presentó un comportamiento a la baja con pequeñas fluctuaciones alrededor de la media de este período que fue de $12,7 \%$, explicado además del cambio de la metodología, por los procesos migratorios de Colombianos hacia el exterior, los cuales se hicieron más evidentes desde 1996.

\section{Salario mínimo en Colombia}

El salario mínimo es el resultado de la formalización por parte del estado de la fijación anual de un estipendio legal básico. En la Figura 6 se puede observar el comportamiento nominal que ha mostrado esta variable en Colombia en el periodo 1980 - 2009.

\section{FIGURA 6. COMPORTAMIENTO DEL SALARIO MÍNIMO NOMINAL EN COLOMBIA 1980 - 2009}

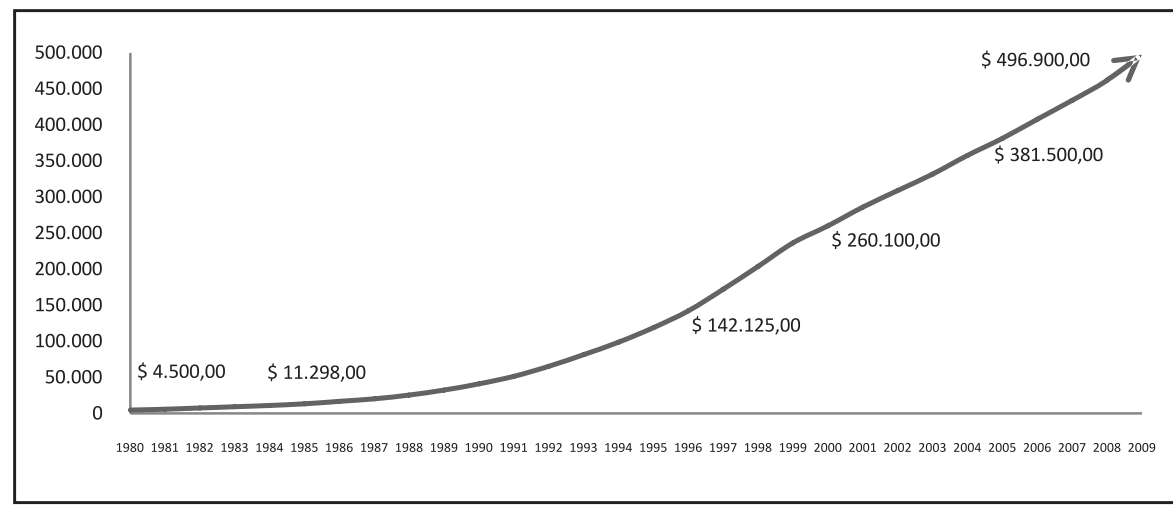

Fuente: diseño de los autores con base en el Departamento Administrativo Nacional de Estadísticas - DANE 
Pero es necesario reconocer, que el comportamiento nominal especialmente en este tipo de variables, no dice mucho, pues lo que realmente interesa, es cuál ha sido el comportamiento del poder adquisitivo real de esta asignación salarial a través de la historia, a lo que se puede aproximar la metodología investigativa en economía, calculando y revisando el indicador salario mínimo real. En respuesta a lo anterior, se presentan datos correspondientes al mismo salario pero deflactado a precios constantes del año 2008, que a continuación se muestra en la Figura 7.

FIGURA 7. COMPORTAMIENTO DEL SALARIO MÍNIMO REAL EN COLOMBIA 1980 - 2009

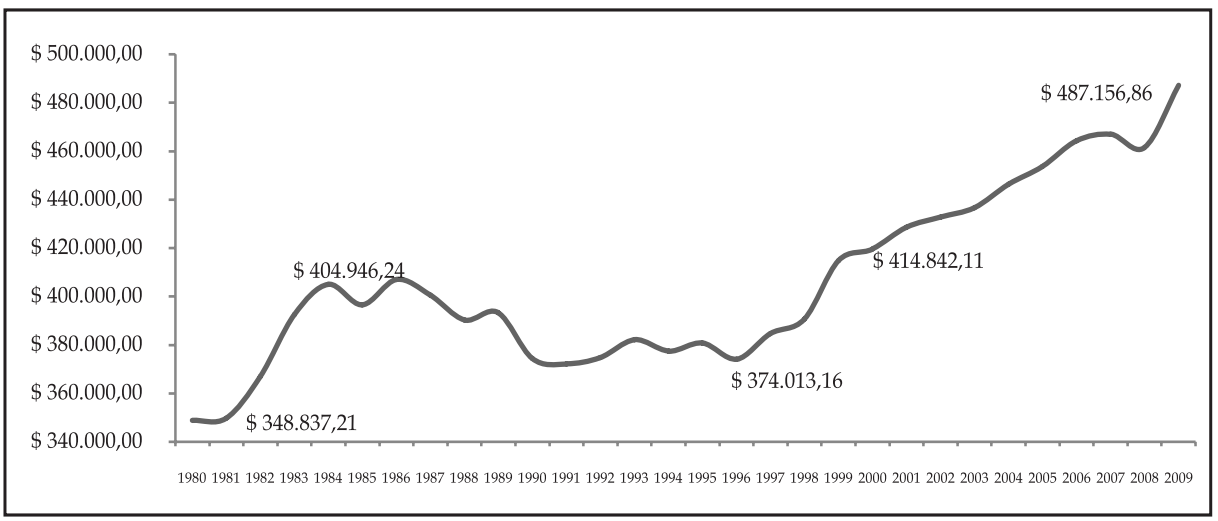

Fuente: diseño de los autores con base en la Comisión Económica Para América Latina - CEPAL (6). 2008=100

Como se observa a primera vista, el Salario Mínimo Real en Colombia ha presentado una tendencia de crecimiento exponencial en el período estudiado, lo que en principio y sin mirar el detalle y el contexto de las cifras, es un muy buen comportamiento frente a la necesidad de mejorar el poder adquisitivo de las familias de más bajos ingresos del país. Esta trayectoria exponencial se ha debido principalmente a algunos cambios mostrados en este período: en primer lugar, desde 1980 hasta 1983 el salario mínimo era reajustado de acuerdo al IPC causado y aumentaba o disminuía de acuerdo a las políticas del gobierno (3). En 1984 se unificó el salario mínimo rural y urbano y quedó uno sólo para todo el país. En 1996 se estableció que el salario mínimo debía ser fijado por la Comisión Permanente de Concertación de Políticas Laborales y Salariales, creada por la Constitución de 1991, pero constituida más tarde con la Ley 278 de 1996.

A pesar de que se regló que la fijación del salario mínimo debía hacerse de acuerdo a la meta de inflación esperada para el año subsiguiente, esto 
no se aplicó en la realidad. Esta ley se modificó en 1999, de acuerdo a la sentencia C-815 de la Corte Constitucional, declarando que además el gobierno debía tener en cuenta la inflación causada del año que culmina, medida según el Índice de Precios al Consumidor, IPC. A partir de 1996, se crea un mecanismo para estabilizar un salario mínimo para la población activa de acuerdo a la inflación (indexación salarial) y que por esta razón el crecimiento de los salarios mínimos corresponde a la proporción del crecimiento de la inflación y otras negociaciones sindicales y gremiales presentes.

\section{PIB per cápita de Colombia}

Por último, se encuentra la variable PIB per cápita de Colombia, un cociente entre el PIB y la población total del país, cuyo comportamiento se presenta en la Figura 8:

FIGURA 8. PIB PER CÁPITA DE COLOMBIA EN DÓLARES 1980 - 2009

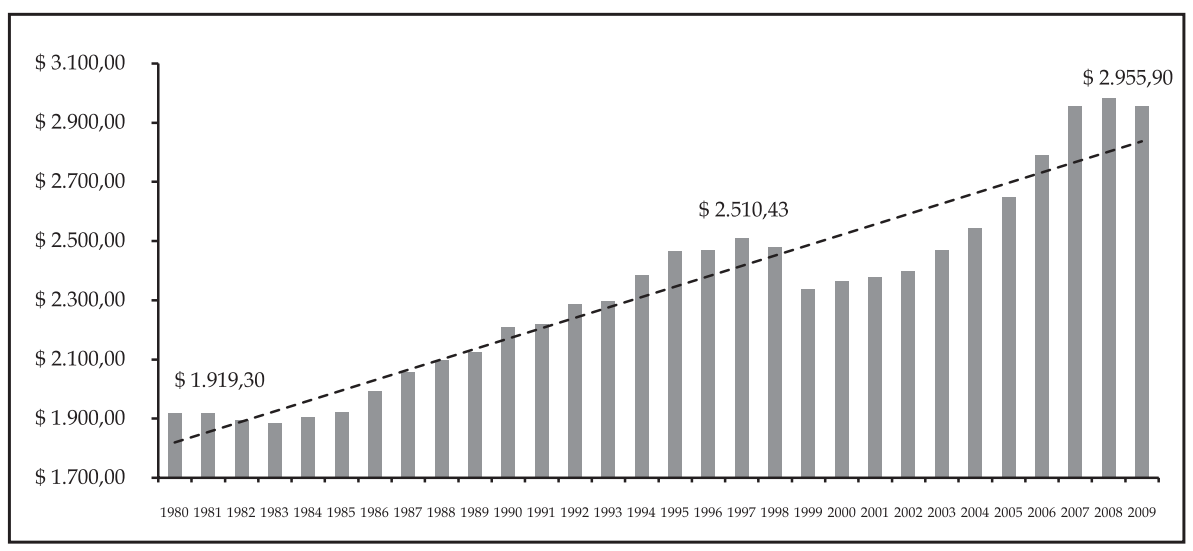

Fuente: diseño de los autores con base en estadísticas del Banco Mundial

Como lo muestra la Figura 8, el PIB per cápita de Colombia en el período de estudio, presenta un comportamiento al alza como lo refleja la línea de tendencia, y además, exhibe fluctuaciones alrededor de la media en este período que fue de 2.328,42 dólares. Sin embargo, para entender el comportamiento real del PIB per cápita es necesario desagregarlo en sus componentes: 


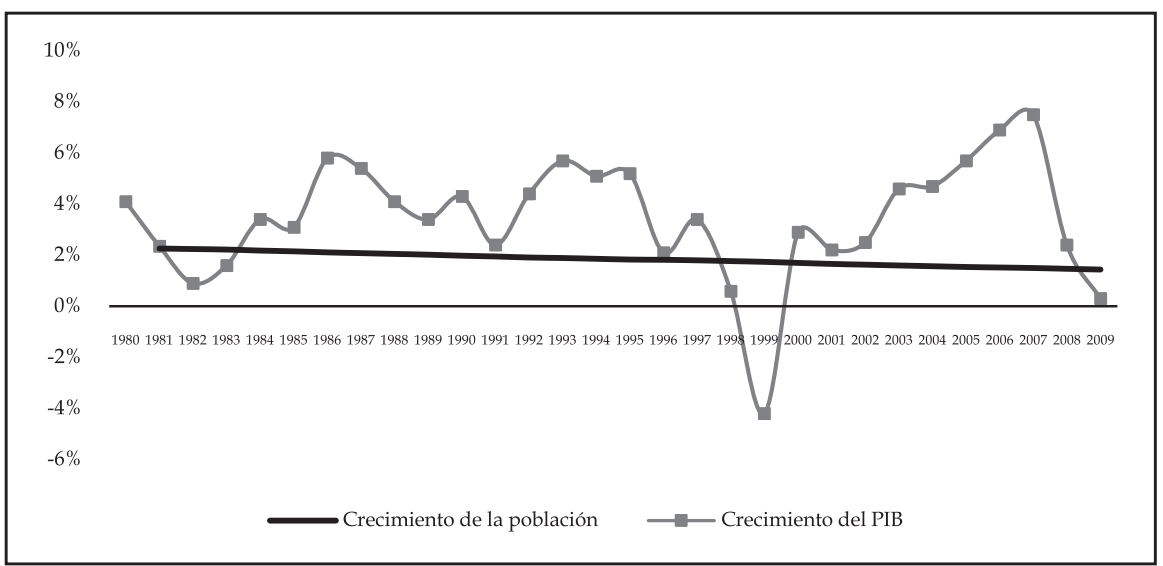

Fuente: diseño de los autores con base en estadísticas del Banco Mundial

En la Figura 9, se observa que la población colombiana ha venido creciendo a una tasa decreciente, pasando de un $2.26 \%$ en 1981 a un $1.44 \%$ en el año 2009. Esto se debe, principalmente a las políticas demográficas implementadas en Colombia para el control de la natalidad y de prevención de enfermedades sexuales contagiosas. Por otra parte, se encuentra al crecimiento del PIB colombiano, que ha sido muy fluctuante a través del tiempo, debido a las crisis mencionadas anteriormente y agregándole la gran crisis financiera mundial del año 2007, 2008 y 2009. Se puede deducir entonces, que las pequeñas fluctuaciones en el PIB per cápita colombiano se encuentran explicadas principalmente por las variaciones del PIB más que por las variaciones de la población, dado que los cambios en ésta ultima variable no han sido muy significativos.

\section{ANÁLISIS FORMAL DEL PROBLEMA: PRESENTACIÓN DEL MODELO}

Corrido el modelo para efectos de análisis y confirmación de las relaciones de causalidad entre las variables implicadas en el problema investigativo, se pudo apreciar que todos los parámetros de las variables son significativos, dado que la probabilidad del estadístico $t$ es menor a 0,05 que es el nivel de significancia. Por el contrario, el $\mathrm{R}^{2}$ resultó ser de 0,333 , lo que indica un mal ajuste en el modelo. No obstante, se puede decir en primera instancia que la relación entre la tasa de desempleo y el salario mínimo es directa, y que la relación entre la tasa de desempleo y el PIB per cápita es inversa (negativa), tal como lo sugiere la teoría. 
$\mathrm{TD}=30.99273-0,010001$ PIBPERCA $+0,0000246 \mathrm{SMR}+\mu$

$\mathrm{t}=(4,22)(-2,77)(3.5333)$

$\mathrm{SE}=(7.3403)(0.0036)(0.00000696)$

Prob $=(0.0002)(0.010)(0.0015)$

Dependent Variable: TD

Method: Least Squares

Date: 11/17/10 Time: 00:44

Sample: 19802009

Included observations: 30

\begin{tabular}{|c|c|c|c|c|}
\hline Variable & Coefficient & Std. Error & $\mathrm{t}$-Statistic & Prob. \\
\hline SMR & $2.46 \mathrm{E}-05$ & $6.96 \mathrm{E}-06$ & 3.533699 & 0.0015 \\
\hline PIBPERCA & -0.010001 & 0.003608 & -2.772087 & 0.0100 \\
\hline $\mathrm{C}$ & 30.99273 & 7.340309 & 4.222264 & 0.0002 \\
\hline R-squared & 0.335650 & Mean dependent var & & 11.94667 \\
\hline Adjusted R-squared & 0.286439 & S.D. dependent var & & 3.101249 \\
\hline S.E. of regression & 2.619704 & Akaike info criterion & & 4.858639 \\
\hline Sum squared resid & 185.2969 & Schwarz criterion & & 4.998759 \\
\hline Log likelihood & -69.87959 & F-statistic & & 6.820620 \\
\hline Durbin-Watson stat & 0.512366 & Prob(F-statistic) & & 0.004003 \\
\hline
\end{tabular}

Normalidad: Se realizó entonces la prueba de normalidad mediante la aplicación del estadístico Jarque-Bera, partiendo de las siguientes hipótesis:

$\mathrm{H}_{0}$ : Los residuos generados por el proceso están distribuidos normalmente. $\mathrm{H}_{1}$ : Los residuos generados por el proceso no están distribuidos normalmente.

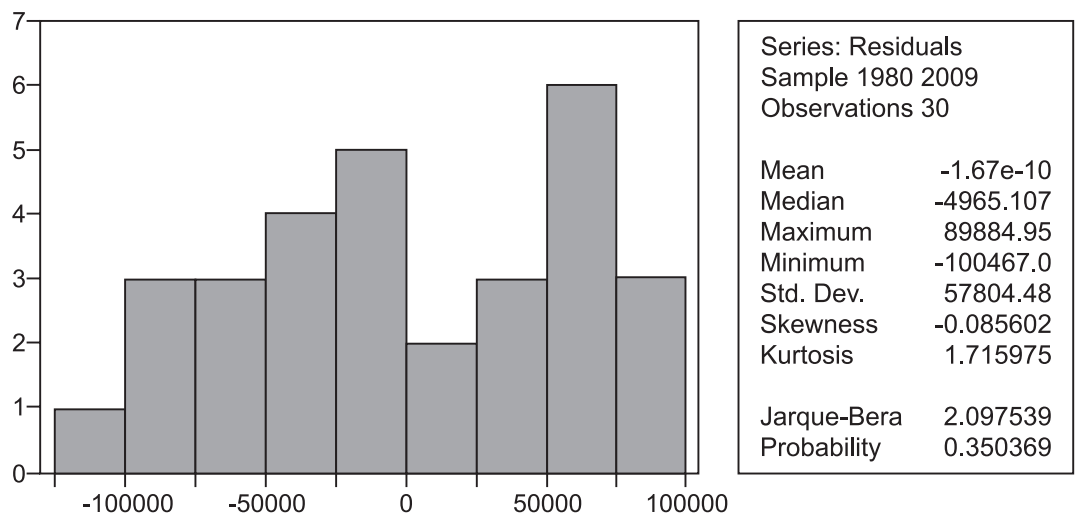


Al resultar la probabilidad de J.B mayor que el nivel de significancia, se acepta H0, con lo que se concluye que los residuos generados por la regresión están distribuidos normalmente, lo que permite que las estimaciones obtenidas a través del método de los mínimos cuadrados sean fiables.

Multicolinealidad:

El problema de multicolinealidad, hace referencia a la dificultad que se presenta cuando las variables independientes o explicativas del modelo, tienen una alta relación entre sí, es decir, que la multicolinealidad se puede plantear como un problema de grado, dicho grado se mide a través del determinante de la matriz de correlaciones, entre más cercano se encuentre éste a 0 el problema de multicolinealidad es cada vez más grave.

\begin{tabular}{|r|r|r|}
\hline 1 & 0,910314248 & 0,382844146 \\
\hline 0,910314248 & 1 & 0,168522962 \\
\hline 0,382844146 & 0,168522962 & 1 \\
\hline
\end{tabular}

DET (matriz de correlaciones) $=0,113821704$

Sabiendo que la multicolinealidad no es un problema de tipo, si no de grado, y observando en este caso el determinante de la matriz de correlaciones que es cercano a 0,12 , se puede decir que el problema de multicolinealidad no es tan grave.

Heteroscedasticidad:

La heteroscedasticidad, hace referencia al problema que se presenta en un modelo econométrico, cuando las varianzas de sus perturbaciones son diferentes para cada una de las observaciones de las variables. Para detectar dicho problema en este modelo, se realizó la prueba de White sin términos cruzados, la cual arrojó lo siguiente:

Como se observa en la anterior salida del Eviews, originada a partir de la prueba de heteroscedasticidad, la probabilidad de $\mathrm{Obs}^{*} \mathrm{R}$-squared $(0,005235)$, es menor que el nivel de significancia $(0,05)$, con lo cual se rechaza la hipótesis nula de no heteroscedasticidad, y se logra detectar que la varianza de las perturbaciones Ui no es constante para todas las observaciones, es decir, se está ante un problema de heteroscedasticidad. 
Autocorrelación:

Para esta investigación se utilizó la Prueba Breusch Godfrey Serial Correlation LM Test para medir la autocorrelación arrojando lo siguiente:

Breusch-Godfrey Serial Correlation LM Test:

\begin{tabular}{|c|c|c|}
\hline F-statistic & 29.98599 Probability & 0.000010 \\
\hline Obs*R-squared & 16.06794 Probability & 0.000061 \\
\hline
\end{tabular}

Test Equation:

Dependent Variable: RESID

Method: Least Squares

Date: 11/17/10 Time: 01:16

Presample missing value lagged residuals set to zero.

\begin{tabular}{lrrrr}
\hline \hline \multicolumn{1}{c}{ Variable } & Coefficient & Std. Error & t-Statistic & Prob. \\
\hline \multicolumn{1}{c}{ PIBPERCA } & 0.002238 & 0.002538 & 0.881483 & 0.3861 \\
SMR & $-4.90 \mathrm{E}-06$ & $4.91 \mathrm{E}-06$ & -0.996129 & 0.3284 \\
C & -4.419223 & 5.160980 & -0.856276 & 0.3997 \\
\multicolumn{1}{c}{ RESID(-1) } & 0.753823 & 0.137661 & 5.475947 & 0.0000 \\
\hline \hline & & & \\
R-squared & 0.535598 & Mean dependent var & & $6.14 \mathrm{E}-15$ \\
Adjusted R-squared & 0.482013 & S.D. dependent var & & 2.527756 \\
S.E. of regression & 1.819258 & Akaike info criterion & & 4.158301 \\
Sum squared resid & 86.05223 & Schwarz criterion & & 4.345127 \\
Log likelihood & -58.37451 & F-statistic & 9.995331 \\
Durbin-Watson stat & 1.735214 & Prob(F-statistic) & & 0.000147 \\
\hline \hline
\end{tabular}

Se puede evidenciar que la probabilidad de RESID (-1), es menor que el nivel de significancia, con lo cual se rechaza la hipótesis nula, y se concluye que los errores se generan bajo un esquema auto regresivo de primer orden, lo que a la vez implica, que se puede utilizar el estadístico de Durbin y Watson, para verificar la existencia de autocorrelacion.

Según los resultados obtenidos a partir de la regresión, el estadístico Durbin y Watson es igual a 0,5170 , contrastado con los valores críticos de DL Y DU, que son 1,284 y 1,567 respectivamente, se encuentra que el estadístico Durbin y Watson cae en la zona de rechazo de la hipótesis nula acerca de no autocorrelacion positiva, por lo cual, existe evidencia estadística para asumir que los residuos del modelo presentan una autocorrelacion serial positiva perfecta, esto implica que los intervalos de confianza para las pruebas $t$ van a ser muy grandes y los valores de $t$ muy pequeños por lo cual es posible que tanto el PIB per cápita como el salario mínimo real no sean estadísticamente significativos, a causa de que los estimadores de los parámetros van a ser totalmente ineficientes. 
Especificación del modelo:

Para verificar si el modelo está correctamente especificado se aplicó la prueba reset de Ramsey, a través del software econometrics Eviews 5.1.

Ramsey RESET Test:

\begin{tabular}{|c|c|c|c|}
\hline F-statistic & 0.060457 & Probability & 0.807705 \\
\hline Log likelihood ratio & 0.069678 & Probability & 0.791807 \\
\hline
\end{tabular}

Test Equation:

Dependent Variable: TD

Method: Least Squares

Date: 11/17/10 Time: 01:10

Sample: 19802009

Included observations: 30

\begin{tabular}{lllll}
\hline \hline Variable & Coefficient & Std. Error & t-Statistic & Prob. \\
\hline \hline PIBPERCA & 0.001729 & 0.047847 & 0.036145 & 0.9714 \\
SMR & $-4.67 \mathrm{E}-06$ & 0.000119 & -0.039158 & 0.9691 \\
C & 1.453861 & 120.3670 & 0.012079 & 0.9905 \\
FITTED^2 $^{\text {R.squared }}$ & 0.049852 & 0.202750 & 0.245881 & 0.8077 \\
\hline \hline Adjusted R-squared & 0.337191 & Mean dependent var & 11.94667 \\
S.E. of regression & 0.260713 & S.D. dependent var & 3.101249 \\
Sum squared resid & 2.666509 & Akaike info criterion & 4.922983 \\
Log likelihood & 184.8670 & Schwarz criterion & 5.109810 \\
Durbin-Watson stat & -69.84475 & F-statistic & 4.409004 \\
\hline \hline
\end{tabular}

Notamos que R-squared no aumenta con la adición de la variable $\mathrm{Y}$ estimado, además se evidencia que la probabilidad de log likelihood ratio es mayor que el nivel se significancia, con lo cual se acepta la hipótesis nula de correcta especificación del modelo y se concluiría que el modelo está bien especificado.

\section{MEDIDAS CORRECTIVAS A LOS PROBLEMAS ENCONTRADOS}

Después de conocer la existencia de problemas (heteroscedasticidad y autocorrelacion), se procedió a transformar logarítmicamente las variables con el fin de corregir el problema de heteroscedasticidad y menguar el de autocorrelacion. 
Dependent Variable: LOGTD

Method: Least Squares

Date: 11/17/10 Time: 01:33

Sample: 19802009

Included observations: 30

\begin{tabular}{|c|c|c|c|c|}
\hline Variable & Coefficient & Std. Error & t-Statistic & Prob. \\
\hline LOGSMR & 0.316636 & 0.054920 & 5.765449 & 0.0000 \\
\hline LOGPIBPERCA & -2.870457 & 0.604498 & -4.748502 & 0.0001 \\
\hline $\mathrm{C}$ & 21.11299 & 4.110492 & 5.136365 & 0.0000 \\
\hline R-squared & 0.573136 & Mean dependent var & & 2.451250 \\
\hline Adjusted R-squared & 0.541516 & S.D. dependent var & & 0.240423 \\
\hline S.E. of regression & 0.162794 & Akaike info criterion & & -0.698027 \\
\hline Sum squared resid & 0.715548 & Schwarz criterion & & -0.557907 \\
\hline Log likelihood & 13.47041 & F-statistic & & 18.12598 \\
\hline Durbin-Watson stat & 0.700235 & Prob(F-statistic) & & 0.000010 \\
\hline
\end{tabular}

Con la aplicación de un modelo log-log (doble logaritmo), se logró corregir el problema de la heteroscedasticidad, lo que implica que los estimadores de los parámetros para las variables PIB per cápita y tasa de desempleo, son con mayor seguridad estadísticamente significativos, aunque el problema de autocorrelación es persistente.

Con esta nueva forma funcional, el modelo quedaría expresado de la siguiente manera:

LOGTD $=21,11299-2,870457$ LOGPIBPERCA + 0,316636 LOGSMR + U

$\mathrm{t}=(5,136365)(-4,748502)(5,765449)$

Std. Error $=(4,110492)(0,604498)(0,054920)$

Prob $=(0,0000)(0,0001)(0,0000)$

Interpretaciones:

- Un aumento del 1\% en el PIB per cápita, provoca una disminución en la tasa de desempleo de $2,8 \%$, con una desviación estándar de $0,6044 \%$.

- Un aumento del $1 \%$ en el salario mínimo real, ocasiona un aumento de la tasa de desempleo de $0,31 \%$, con una desviación estándar de $0,0549 \%$. 


\section{CONCLUSIONES}

1. De acuerdo a las elasticidades obtenidas en el modelo, para el caso colombiano la tasa de desempleo es más sensible a variaciones en el PIB Per Cápita, que a variaciones en el Salario Mínimo real.

2. El salario mínimo real ejerce poca o casi nula influencia sobre el comportamiento de la tasa de desempleo. Esta situación va totalmente en contra del análisis planteado por la teoría keynesiana, en donde uno de los determinantes de aumentos en la tasa de desempleo era el comportamiento del salario mínimo, al afirmar que cuando este aumentaba por encima del mostrado por el mercado, se generaba un desempleo involuntario.

3. Las variables explicativas (PIB Per Cápita y Salario Mínimo real), solo terminan explicando el $57 \%$ de las variaciones presentadas por la tasa de desempleo, esto nos da una idea clara de que la tasa de desempleo, está influenciada por otras variables, que por fines metodológicos y de focalización del interés investigativo, no fueron incluidas en el modelo.

4. Debido a que no se pudo corregir el problema de autocorrelacion, es posible que los estimadores obtenidos mediante el método de los mínimos cuadrados ordinarios sean ineficientes, lo cual no garantiza de manera integral que los coeficientes del PIB Per Cápita y el Salario Mínimo real, sean efectivamente estadísticamente significativos.

\section{REFERENCIAS BIBLIOGRÁFICAS}

1. Ortega, Daniel. Causas del Desempleo, Salario Mínimo y Costos de Largo Plazo. Sitio Web Enciclopedia y Biblioteca Virtual de las Ciencias Sociales, Económicas y Jurídicas. [En línea] [Citado el: 3 de Noviembre de 2010.] http:/ / www.causas\%20del\%20desempleo, $\% 20$ salario $\% 20$ minimo $\% 20 \mathrm{y} \% 20 \operatorname{costos} \% 20$ de $\% 201$ p.pdf.pdf.

2. Nuñez Mendez, Jairo y Bonilla, Juan Diego. ¿Quiénes se perjudican con el salario mínimo en Colombia?. 24, Bogotá: FEDESARROLLO, 2001.

3. Robbins, Donald J. Empleo y Desempleo en Colombia el Impacto de la Legislación y de las Políticas Salariales (1976-1999). Bogotá - Colombia: Pontificia Universidad Javeriana, 2003. 958683648-7.

4. Ruiz, Reinaldo. Salario mínimo:consideraciones económicas y sociales para su determinación. 28, Talca - Chile: Universidad de Talca, 2004.

5. Hernández Díaz, Gustavo y Pinzón García, Enrique. El Efector del salario mínimo sobre el empleo y los ingresos. Departamento Nacional de Planeación - Dirección de Estudios Económicos. [En línea] 1 de 
Septiembre de 2006. http://www.dnp.gov.co/Portals/0/archivos/ documentos/DEE/Archivos_Economia/316.pdf.

6. Steiner, R. y García, O. ¿Por qué se requieren reformas al mercado laboral y al sistema pensional? 328, Bogotá - Colombia: Contraloría General de la República, 2009.

7. Banco Central del Ecuador. Banco Central del Ecuador. [En línea] [Citado el: 16 de Noviembre de 2010.] http://www.bce.fin.ec/ resumen_ticker.php?ticker_value $=$ desempleo.

8. Hernández Sampieri, Roberto, Fernández Collado, Carlos y Batista Lucio, Pilar. Metodología de la Investigación. México: Mc Graw-Hill, 2010.

9. Arango, Luis Eduardo, Herrera, Paula y Posada, Carlos Esteban. El salario mínimo: aspectos generales sobre los casos de Colombia y otros países. 56, s.l.: Banco de la República, 2008, Vol. 26.

10. Desormeaux, Nicolás. Salarios de eficiencia y productividad. Universidad Técnica Federico Santa María. [En línea] 19 de Mayo de 2010. [Citado el: 2010 de Noviembre de 11.] http://www. ceas.usm.cl/documentos/Estudios/Desempleo/Documento $\% 20$ de $\%$ 20Trabajo \% 20-\% 20Salarios \% 20de \% 20Eficiencia \% 20y \% 20 Productividad.pdf.

11. Congreso de la República de Colombia. Ley 6 de 1945 - Régimen del Empleado Oficial. DMS Ediciones Jurídicas. [En línea] [Citado el: 1 de Enero de 2011.] http://www.dmsjuridica.com/CODIGOS/ REGIMENES/REG_EMPLEADO_OFICIAL/REG_EMPLEADO_ OFICIAL.htm.

12. - . Constitución Política de Colombia 1991. Banco de la República. [En línea] [Citado el: 11 de Enero de 2011.] http//www.banrep.gov. $\mathrm{co} /$ regimen/resoluciones/cp91.pdf.

13. - - Ley 278 de1996-Comisión Permanente de Concertación dePolíticas Salariales y Laborales creadas por el Artículo 56 de la Constitución Política de Colombia. Secretaría del Senado. [En línea] 10 de Mayo de 1996. [Citado el: 11 de Enero de 2011.] http:/ / www.secretariasenado. gov.co/senado/basedoc/ley/1996/ley_0278_1996.html.

14. Kalmanovitz, Salomón. Recesión y recuperación de la Economía Colombiana. 192, Buenos Aires - Argentina: Nueva Sociedad, 2004.

15. Banco Mundial. Banco Mundial. [En línea] [Citado el: 16 de Noviembre de 2010.] http:/ / datos.bancomundial.org/indicador.

16. Comisión Económica Para América Latina - CEPAL-. Estadísticas y series históricas. Websie.eclac.cl. [En línea] [Citado el:16 de Noviembre de 2010.] http:/ / websie.eclac.cl/sisgen/ConsultaIntegrada.asp. 